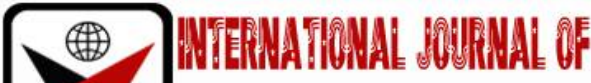

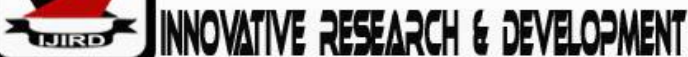

ISSN 2278-0211 (Online)

\section{Design and Development of Plastic Crusher for a More Efficient Waste Management Practice}

\author{
Muyiwa A. Okusanya \\ Lecturer, Department of Agricultural and Bioenvironmental Engineering, \\ Federal Polytechnic Ilaro, Ogun State, Nigeria \\ Gbenga W. Ibrahim \\ Lecturer, Department of Mechanical Engineering, \\ Federal Polytechnic Ilaro, Ogun State, Nigeria
}

\begin{abstract}
:
One of the prevalent environmental problems encountered in most developing countries is solid waste management. Plastic waste such as polyethylene terephthalate (PET) bottles and other plastic materials is one of the solid wastes hampering the developmental and aesthetical state of our environment. This is as a result of indiscriminate disposal and indiscriminate burning of solid waste. Environmental pollution caused by this indiscriminate disposal and burning necessitated the development of plastic crusher to recycle plastic waste generated within our environment. The machine components are hopper, crushing chamber, crushed material outlet, counter weight, transmission shaft with spiral blade around it, channel and body frame. The machine is powered by a 3-phase 10Hp medium speed electric motor. The machine, being a medium sized crusher, has the capacity of crushing half a ton of plastic in a day depending on the type of recyclable plastic crushed. The degree of linear correlation, $r$ squared for observed and predicted values of variables evaluated are within acceptable region. The efficiency of crushing based on polymers processed are $90 \%$ for HDPE, 68\% for LDPE, 45\% for PVC and 10\% for PET bottles. The developed crusher can be used to reduce the volume of plastic waste dump. If the findings from this technical brief is adopted and commercialized, the menace of plastic waste will be ended.
\end{abstract}

Keywords: Polyethylene Terephthalate (PET), High Density Polyethylene (HDPE), Polyvinyl Chloride (PVC), Low Density Polyethylene (LDPE), Plastic Waste Management

\section{Introduction}

\subsection{Background Information of the Study}

Plastic is a synthetic material made from a wide range of organic polymers such as polyethylene terephthalate (PET), high density polyethylene (HDPE), Polyvinyl chloride (PVC) and low-density polyethylene (LDPE) that can be moulded into a rigid or slightly elastic form. Plastic materials produced from oil by a chemical process are nonbiodegradable, light in weight and do not break easily. Any property of a large number of synthetic polymers materials usually organic that have a polymeric structure and can be moulded when soft and then set, such materials are subspecies of a class of materials known as polymers. These are composed of large molecules formed by joining many, often thousands of smaller molecules (monomers) together. Other kind of polymers is fine, film, elastomers (rubber) and biopolymers.

The plastic industry, owing to its use in a wide variety of sectors, such as the automotive, construction, electronics, healthcare, textiles, drink industry, etc., is amongst the fastest growing markets. (RRN Bhattacharya, 2018). As the world's population continues to grow by leaps and bound, so does the amount of plastic waste that people produce. On-the-go lifestyles require easily disposable products, such as soda cans or bottles of water and soft drink, but the accumulation of these products has led to increasing amounts of plastic pollution around the world. As plastic is composed of major toxic pollutants, it has the potential to cause great harm to the air, water and land. (Amandeep, 2019).

Plastic pollution is when plastic has gathered in an area and has begun to negatively impact the natural environment and create problems for plants, wildlife and even human population. Often, this includes killing plant life and posing dangers to local animals. Plastic is an incredibly useful material, but it is also made from toxic compounds known to cause illness, and because it is meant for durability, it is not biodegradable. (Amandeep. 2019).

Plastic waste is a constituent of the solid waste stream of which polyethylene terephthalate (PET) is a part. PET is used to produce plastic bottle and several other plastic products. Most bottles produced by PET are transparent in nature and are used for packaging water, soda etc. Plastic are non- bio degradable. It prevents or reduces the seepage of water into the soil. They clog/block the domestic pipelines and sewage lines. Direct burning of plastic leads to the emission of 
toxic fumes and gases, which in turn affect human health. Emission of carbon dioxide during burning of waste plastics causes rise in earth temperature i.e. global warming. Better industrial practices have led to minimizing exposure of plant workers to harmful fumes. For example, there have been problems in the past resulting from worker being exposed to toxic vinyl chloride vapour during the production of polyvinyl chloride. Many chemical ingredients of plastics are highly carcinogenic.

According to Bhattacharya (the sustainable alternatives that could be considered to deal with plastic one of ,(2018 and poly lactic acid as raw materials for ,cellulose ,based and biodegradable plastic which utilizes starch-waste is to develop bio te-shortrm use products. However, these are more expensive and are presently at a lab scale, which needs to be up scaled. It was further reported that incentive-/subsidy-based strategies for product development and research would assist in facilitating this up scaling into biodegradable plastics. Applications of bio-based products extend to the manufacturing of green packaging, disposable cutlery, agricultural mulch films, and manufacturing of superabsorbent materials, that can be used for a sustained release of pesticide/fertilizer in the agricultural sector. Further, these can also be used as eco-friendly alternatives for the removal of toxic dyes and heavy-metal contaminants from water bodies. (Bhattacharya, (2018

Plastic bottles are made from petroleum product known as polyethylene terephthalate (PET) and they require huge amount of fossils fuels to both make and transport them. It is harder to recycle plastic bottles than one thinks. Some plastic bottles consumed throughout the world, most of them are not recycled because only certain types of plastic bottle can be recycled by certain municipalities. This simply means that more resources are being used to meet the increasing demand for plastic. Thus, more waste is generated in this line, and to reduce some of these problems, plastic crushing machine was designed, fabricated and tested in the department of Agricultural and Bio Environmental Engineering technology, Federal Polytechnic Ilaro, Ogun State, Nigeria, to recycle plastic waste constituting menace around the metropolis.

Nitulet al (2015) studied the overview of recycle of various types of plastics. The report reveals that plastics are generally categorized into two types namely, recyclable and non-recyclable types. The recyclable plastics are PET, HDPE, LDPE, PVC, etc. while non-recyclable is plastic Bakelite, Nylon, etc. Sorting, Cleaning, Shredding, crushing and extrusion are the general steps which are involved in recycling plastics. This research endeavour focuses on one of major processes involved in recycling plastic, plastic crushing.

Plastic crusher is a machine that reduces used plastic bottles to smaller particle sizes to enhance its portability, easiness and readiness for use into another new product. Plastic crusher designed and constructed comprises of four major components namely; the feeding unit, the crushing chamber unit, the power unit and the machine frame.

\section{Literature Review}

\subsection{Common Plastic Types}

Plastics are synthetic materials made from a wide range of organic polymers that can be moulded into a rigid or slightly elastic form. They are malleable solids that have strong resistant to corrosion and chemicals. Owing to the fact that they are cheap and light in weight, a wide variety of sectors, such as the automotive, construction, electronics, healthcare, textiles, drink industry, etc., use them as either component part of their products or as packaging materials. Plastic industry is therefore amongst the fastest growing markets in the world. The common types are polyethylene terephthalate (PET), high density polyethylene (HDPE), Polyvinyl chloride (PVC) and low-density polyethylene (LDPE), Polypropylene (PP), Polystyrene (PS), Polyethylene (PE), Acrylonitrile-Butadiene-Styrene (ABS), Polycarbonate (PC) etc.

\subsection{Plastic Waste Management Problems}

Plastics are polymers, a very large molecule made up of smaller units called monomers which are joined together in a chain by a process called polymerization. The polymers generally contain carbon and hydrogen with, sometimes, other elements such as oxygen, nitrogen, chlorine or fluorine. Plastics have become an integral part of our lives. The amount of plastics consumed annually has been growing steadily as the population growth is on steady increase. Its low density, strength, user-friendly designs, fabrication capabilities, long life, lightweight, and low cost are other factors behind the excessive accumulation of plastic waste.

Plastics have been used in packaging, automotive and industrial applications, medical delivery systems, artificial implants, other healthcare applications, water desalination, land/soil conservation, flood prevention, preservation and distribution of food, housing, communication materials, security systems, and other uses. With such large and varying applications, plastics contribute to an ever-increasing volume in the solid waste stream.

The world's annual consumption of plastic materials has increased from around 5 million tons in the 1950s to nearly 320 million tons in 2015 (Beckman, 2018). Quantities of waste plastics have been rising rapidly during the recent decades due to high increase in industrialization and the considerable improvement in the standards of living. Unfortunately, majority of these waste quantities are not being recycled but rather abandoned causing certain serious problems such as the waste of natural resources and environmental pollution (See plates 1 and 2 below for details of pollution impact of plastic).

In the recycle industry, the component must be crushed or melted to form a pellet. Therefore, the plastic bottle must be cut into smaller pieces appropriate with the machine condition before it is then transferred to the industry as raw material for further processes such as injection moulding (Vanessa Goodship, 2007). There are two systems used in crushing machine, namely impact system and rotary system. 


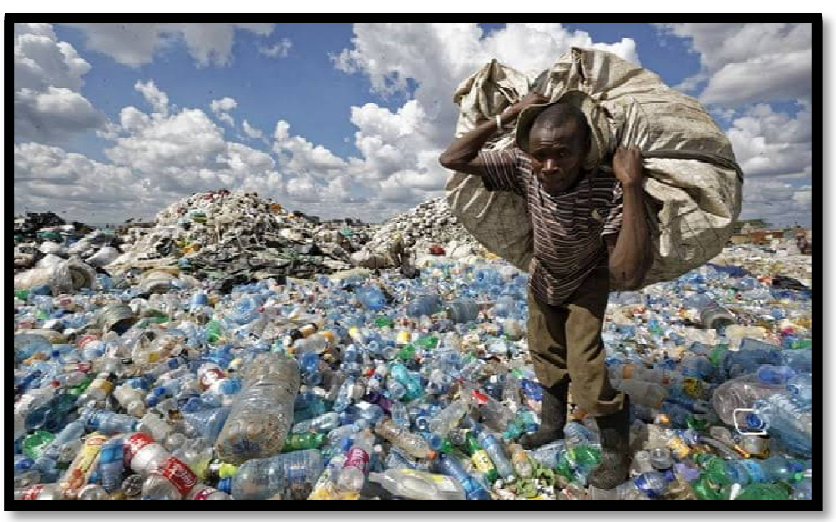

Figure 1: Plastic Waste Dump at Idimu Area, Lagos, Nigeria

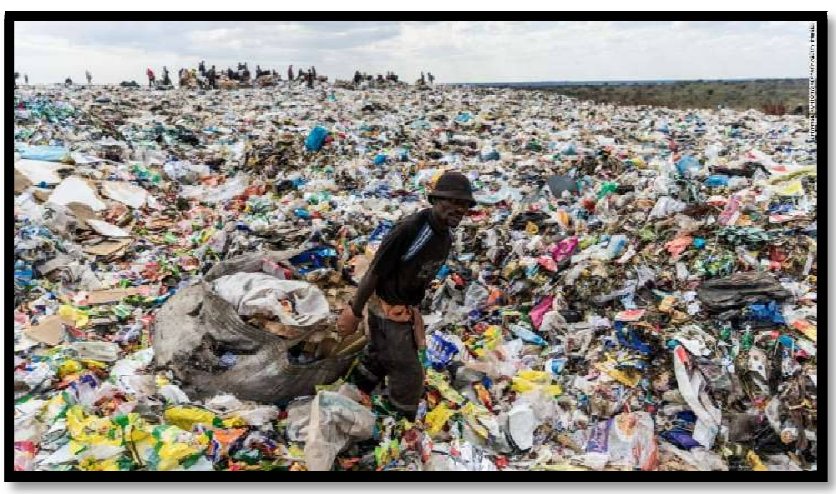

Figure 2: Waste Dump at Egbeda Area, Lagos, Nigeria

\subsection{Causes of Plastic Waste Management Problems in Nigeria}

Plastics are synthetic organic materials produced by polymerization. They are non-bio degradable materials and can stay unchanged for as long as 4500 years on earth causing menace to our land, streams and drainage system.

The plastic waste percentage of waste generated by humans is high and this causes a lot of environmental pollution like eyesore and leachate generation from land filling, dioxin and photochemical smog from incineration, etc.

Indiscriminate disposal and indiscriminate burning of plastic waste are the root cause of exponential increase in pollution index of most urban and industrial settlements like Lagos and Ogun State, Nigeria. Other causes of waste management problems are: population increase; increased level of urbanisation and industrialisation; culture of turning waste to wealth that is not popular in developing economies; and regulatory policies on environmental cleanliness that are not popular. So as to reduce the effect of plastic waste impact, a plastic crusher became the focus of this technical brief.

\subsection{Methods of Plastic Waste Management}

In reducing toxic effects of plastic wastes on the environment and public health, waste management plays a major role. For global reduction of plastic litters and ocean pollution, there is need for improvement in proper plastic waste collection, treatment and disposal (Jambeck et al, 2015). Various methods of plastic waste management in practice are land filling, incineration, gasification, pyrolysis, bio-plastic adoption, reuse and recycling.

\subsubsection{Land Filling}

A landfill is often thought of as a big hole in the ground where bulldozers indiscriminately plough solid waste into the earth. In most cases, landfills are municipal solid waste facilities that collect and bury whatever is not sent to municipal recovery facilities. This includes food waste, paper, glass, plastic and other products that could otherwise be recycled. Inadequate management of landfills will make way for harmful chemicals in plastic wastes to leach into the environment, polluting the soil, air and underground water (Jambeck et al, 2015). This waste management practice should be discouraged as much as possible as its major drawback (eyesore and seepage of leachate into underground water) affect humans and endangers plants and animal life.

\subsubsection{Incineration}

Incineration is a waste treatment process that involves the combustion of solid substances contained in waste materials (Knox, 2005).Incineration and other high-temperature waste treatment systems are described as thermal treatment as it converts waste materials into ash, flue gas and heat. Empirical facts gathered reveal that fossil fuel causes climate changes. What is less known is that plastic is also a climate polluter, as it is made from fossil fuels, such as crude oil, coal, and natural gas. Although, incineration is one of the common ways to manage plastic waste effectively, burning plastic creates harmful dioxins and if incinerators are inefficient, these leak into the environment causing air pollution, dioxin emissions, bisphenol and photochemical smog that are carcinogenic to human health. 


\subsubsection{Bio-Plastics Adoption (Eco-Friendly Alternative)}

According to Bhattacharya (one of the sustainable alternatives that could be considered to deal with plastic ,2018 and poly lac ,cellulose ,based and biodegradable plastic which utilizes starch-is to develop bio wastetic acid as raw materials for short-term use products. However, these eco-friendly alternatives are more expensive and are presently at a lab scale; the research needs to be up scaled.

\subsubsection{Reuse}

It is difficult to make it through a day without acquiring some form of plastic. That is where reuse comes in. Once plastic is in one's possession, one has chance to be creative and find different usages for it. Also, anything that cannot be reused can be donated as it will serve to help others who are in need of it. Most people skip this step and go directly to recycling, but reusing plastics can reduce the demand for new plastics to be created. The drawback this method of waste management has is in its adoption for corporate businesses where products have to be sealed to promote hygiene of practice. Figure 3 below shows the picture of an on-going constructional work with PET bottles and concrete blocks at tourism village of Federal Polytechnic Ilaro (FPI), Ogun State, Nigeria.

Empirical facts gathered from published work reveal that plastic waste can be used in road construction projects. As we search for new ways to use plastic, using it in roads provides literally miles and miles of possibilities. If the sheer volume of plastic waste generated by the municipal is channelled to meet the requirements for road construction and their upkeep, there is a future that helps to take care of waste management problem in our environment (Poweth et al, 2018). Micro plastic is in good turn homogenised into polymer-modified bitumen before it is used for road construction to avoid accumulation of leachate which then sips into nearby water table to pollute it.

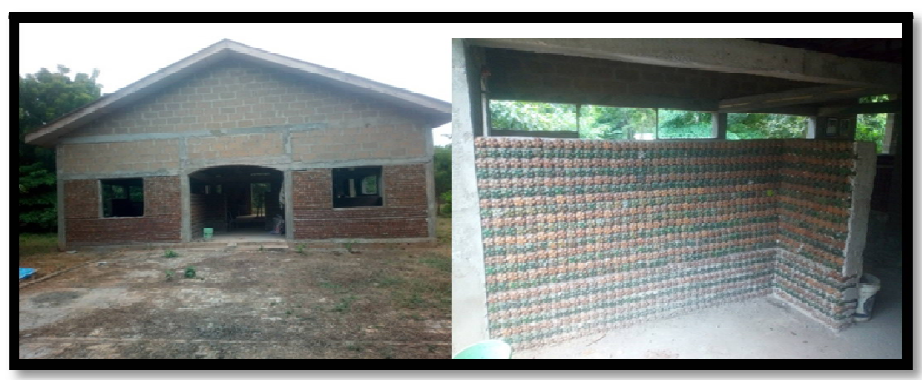

Figure 3: Use of PET Bottles Waste for Building Construction Attourism Village, FPI

\subsubsection{Recycling}

Recycling is a good option after plastic has been reused as many times as one can and one is ready to dispose of it. Recycling plastic takes less energy than making plastic from raw materials. However, with a little planning, commitment and effort, it is easy to make steps towards reducing one's carbon footprint. The biggest impact is made by avoiding plastics in the first place and if that cannot be done, reuse and recycling are the next best steps. Conscious effort should be made to reduce the amount of plastic material being used by trying to replace plastic with something more sustainable whenever possible. Any plastic that has already been acquired can be reused. More also, used plastic can be recycled to keep it out of the waste stream as this will serve to reduce demand for new plastic. Recycling will help to reduce plastic pollution and keep our planet clean and healthy for future generations. The drawback with this practice is waste collection problems, sorting problem and high initial cost of machines used in recycling the plastic.

\subsection{Recyclable and Non-Recyclable Plastic}

Recyclable plastic materials are materials once collected can be turned into new products while non-recyclable plastic materials are the types that cannot be processed into new product after use. The recyclable types are thermoplastics while the non-recyclable are thermosets. A thermoplastic is a material usually a plastic polymer which becomes softer when heated and hard when cooled. Thermoplastic materials can be cooled and heated several times without any change in their chemical or mechanical properties. They can be repeatedly reformed into new products. Thermoplastic polymers are the focus of this technical brief. The thermosetting polymers on the other hand are materials which remain in a permanent solid state after being cured one time. Direct implication is that thermosets will not melt even when exposed to extremely high temperatures. They are often used in electrical applications and are not suitable for recycling in most cases. Examples of recyclable plastic are PET bottles, HDPE, LDPE, PVC, acrylic, polyester etc. while the unrecyclable types are polyester resin, polyurethanes, vulcanized rubber, bakelite, vinyl ester and thiolyte used as electrical insulating materials.

\subsection{Steps Involved in Recycling Plastics}

Plastic recycling refers to the process of recovering waste or scrap plastic and reprocessing the materials into functional and useful products. This activity is known as the plastic recycling process. The goal of recycling plastic is to reduce high rates of plastic pollution while putting less pressure on virgin materials to produce brand new plastic products. This approach helps to conserve resources and diverts plastics from landfills or unintended destinations such as oceans or water courses leading to the municipal. 
Plastic recycling is broken up into a few distinct steps. Generally, these steps remain the same for most types of recycling facilities, but certain steps can be combined or omitted in some situations. The steps involved are:

- Plastics collection - common practice involves road side collections, use of special recycling bins, direct collection from industry, etc.;

- Manual sorting - various plastics collected are sorted into PET, HDPE, LDPE, PVC, etc.;

- Chipping - machines like crusher, shredder, bailer, etc. Are used to reduce the size of the polymer under process into desired granular size;

- Washing - washing of shredded plastic assist in removing contaminant from the materials before they are then taken to the next stage of the process.

- Pelleting - machines like extruder, pelletizer, etc. Are used in turning the shredded and washed plastics into pellets under intense heat and pressure. Pelleted plastics are afterwards sold as raw materials for other processes like making of PET bottles, PVC pipes, buckets, etc.

\subsection{Benefits of Recycling}

The benefits of waste recycling include the following:

- The process of recycling plastic helps waste management by saving available space in landfills.

- Recycling conserves the natural resources and the energy that would be required to produce plastic from scratch.

- Plastic Recycling helps in mitigating global warming and reducing pollution

- Wealth generation - there are companies that pay cash for trash and patronizing the recycled products saves money because they are less expensive.

- Plastic Recycling recovers the scrap or the waste plastic and reprocesses the material into useful products.

- Plastic Recycling protects the environment.

- Plastic recycling promotes judicial and sustainable use of resources

- Plastic recycling creates green jobs.

Despite the efficiencies and benefits of most recycling facilities, there can still be some difficulties involved with the process of recycling plastic. Materials such as dyes, heavy metals, pharmaceuticals, and sometimes pieces of biodegradable plastic can potentially contaminate an entire batch of petroleum-based plastics and it will all need to be thrown away. This is why it is very important for one to follow the guidelines of one's recycling company regarding which plastics can and cannot be accepted for recycling.

\section{Materials and Methods}

\subsection{Design Consideration}

Some relevant factors were considered in the design and development of the crusher; such factors are cost of maintenance, power requirement and ease of replacement of various components and labour requirement. The machine is easy to maintain. Mild steel plate of $6 \mathrm{~mm}$ thickness was considered for the construction to avoid shearing of parts and eventual machine failure while in operation. The spiral shaft impacts strong impact force on the crushing chamber to achieve crushing into desired granular size, materials fed into it.

\subsection{Component Parts of the Machine}

Plastic crusher is a machine that reduces used plastic to smaller particle sizes to enhance its portability, easiness and readiness for use into another new product. Plastic crusher designed and constructed comprises of the following parts:

- Hopper: is the section through which the waste plastic is fed into the crushing chamber. It is made up of mild steel of $6 \mathrm{~mm}$ thickness with dimension of $480 \mathrm{~mm} \times 300 \mathrm{~mm} \times 427 \mathrm{~mm}$.

- Crushing chamber: The crushing unit is where the waste plastic is cut into smaller sizes either through shredding or impact force of a crusher or shredder as the case may be. The crushing chamber consists of a shaft that is 539 $\mathrm{mm}$ length and $65 \mathrm{~mm}$ in diameter. Attached to the shaft are cutters made of $12 \mathrm{~mm}$ mild steel flat blade of $270 \mathrm{~mm} \times 74 \mathrm{~mm}$ welded to $270 \mathrm{~mm}$ cylindrical drum to form spiral blade.

- Transmission shaft: The shaft is made up of cast iron block of $539 \mathrm{~mm}$ length and $40 \mathrm{~mm}$ in diameter

- Spiral blade: The spiral blade cut the plastic into granules with its sharp edges. It is made up of $12 \mathrm{~mm}$ thick mild steel of dimension $270 \mathrm{~mm} \times 74 \mathrm{~mm}$.

- Screen: The screen is of dimension $375 \mathrm{~mm}$ length and 392 diameter. The pore space on the screen is $8 \mathrm{~mm}$ in diameter.

- Bearing: Bearing is a mechanical device that supports another part and reduces friction. The type of bearing used is pillow bearing.

- $\quad$ Belt drive: A band that used to transfer power or motion from the pulley of the prime mover to the transmission shaft pulley.

- Counter weight: This is a heavy mass of iron mechanically linked in opposition to a load. It supports the machine and maintains balancing.

- Member frame: The frame supports the other component parts on it in order to make the entire assemble stable. It is made up of mild steel of $480 \mathrm{~mm} \times 480 \mathrm{~mm} \times 400 \mathrm{~mm}$. 
- Discharge outlet: The crushed plastic passes through an outlet provided at the peripheral of the machine. It is made up of mild steel of dimension $378 \mathrm{~mm} \times 151 \mathrm{~mm} \times 110 \mathrm{~mm}$.

- Prime mover: is a machine that receives and modifies energy as supplied by some natural sources or fuel and transform it into mechanical work. It is powered by electric motor of $10 \mathrm{hp}$.

- Channel: It is the platform that maintains the stability of the machine. It carries the load and weight of the machine. It is made up of angle iron.

\subsection{Material Selection}

\begin{tabular}{|c|c|c|c|c|}
\hline $\begin{array}{c}\text { Machine } \\
\text { Component }\end{array}$ & $\begin{array}{c}\text { Criteria For } \\
\text { Material Selection }\end{array}$ & Machine Selected & Dimension & Remark \\
\hline Hopper & $\begin{array}{l}\text { Must be strong and } \\
\text { able to acquire } \\
\text { more material }\end{array}$ & $\begin{array}{l}\text { Mild steel of } 6 \mathrm{~mm} \\
\text { thickness }\end{array}$ & $\begin{array}{c}400 \mathrm{~mm} \times 300 \mathrm{~mm} \times \\
427 \mathrm{~mm}\end{array}$ & $\begin{array}{l}\text { It does not twist } \\
\text { and has ability to } \\
\text { occupy more } \\
\text { material } \\
\text { (fabricated) }\end{array}$ \\
\hline Crushing chamber & $\begin{array}{l}\text { Ability to withstand } \\
\text { spiral blade } \\
\text { vibration and } \\
\text { impact force }\end{array}$ & $\begin{array}{l}\text { Mild steel of } 6 \mathrm{~mm} \\
\text { thickness }\end{array}$ & $\begin{array}{c}394 \mathrm{~mm} \times 394 \mathrm{~mm} \times \\
250 \mathrm{~mm}\end{array}$ & $\begin{array}{c}\text { Durable } \\
\text { (fabricated) }\end{array}$ \\
\hline Shaft & Must be strong & Iron rod & $\begin{array}{c}539 \mathrm{~mm} \text { long and } \phi \\
40 \mathrm{~mm}\end{array}$ & It was machined \\
\hline Spiral blade & $\begin{array}{l}\text { Must be strong and } \\
\text { have sharp cutting } \\
\text { edges }\end{array}$ & $\begin{array}{l}\text { Mild steel of } 12 \mathrm{~mm} \\
\text { thickness }\end{array}$ & $270 \mathrm{~mm} \times 74 \mathrm{~mm}$ & $\begin{array}{l}\text { It has strong and } \\
\text { sharp edges for } \\
\text { crushing(machined) }\end{array}$ \\
\hline Screen & $\begin{array}{c}\text { Ability for ease of } \\
\text { passage of material } \\
\text { under process }\end{array}$ & $\begin{array}{l}\text { Mild steel of } 3 \mathrm{~mm} \\
\text { thickness }\end{array}$ & $275 \mathrm{~mm} \times 392 \mathrm{~mm}$ & $\begin{array}{l}\text { Available (bought } \\
\text { readymade) }\end{array}$ \\
\hline Belt & $\begin{array}{c}\text { Must be strong and } \\
\text { not flexible }\end{array}$ & Leather & B64 & $\begin{array}{l}\text { Stable (bought } \\
\text { readymade) }\end{array}$ \\
\hline Pulley & $\begin{array}{c}\text { Ability to have a } \\
\text { good wear } \\
\text { property }\end{array}$ & Cast iron block & $200 \mathrm{~mm} \times 75 \mathrm{~mm}$ & Bought readymade \\
\hline Bearing & $\begin{array}{l}\text { Must be durable } \\
\text { and strong }\end{array}$ & Mild steel & $\begin{array}{l}\text { Pillow bearing of } \\
40 \mathrm{~m} \text { internal bore }\end{array}$ & Bought readymade \\
\hline Counter weight & $\begin{array}{l}\text { Ability to withstand } \\
\text { load of the shaft for } \\
\text { balancing }\end{array}$ & Cast Iron block & $200 \mathrm{~mm} \times 75 \mathrm{~mm}$ & $\begin{array}{l}\text { Available and } \\
\text { durable }\end{array}$ \\
\hline Channel & $\begin{array}{c}\text { Must able to } \\
\text { withstand dead } \\
\text { load imposed by } \\
\text { the self-weight of } \\
\text { the crusher }\end{array}$ & $\begin{array}{l}\text { Angle iron of } 6 \mathrm{~mm} \\
\text { thickness }\end{array}$ & $\begin{array}{c}1047 \mathrm{~mm} \times 365 \mathrm{~mm} \\
\times 80 \mathrm{~mm}\end{array}$ & Constructed \\
\hline Bolts and nuts & $\begin{array}{c}\text { Must be hard and } \\
\text { durable }\end{array}$ & Alloy steel & & Bought readymade \\
\hline Prime mover & $\begin{array}{c}\text { Must be a medium } \\
\text { or high speed }\end{array}$ & Electric motor & $10 \mathrm{hp}$ & Bought readymade \\
\hline
\end{tabular}

Table 1: Material Selection

\subsection{Machine Description and Operation}

The waste plastic crusher has four main components; the feeding unit, the crushing unit, the power unit and the machine frame (See figure 2, 3and 4for details on pictorial view, orthographic projection and part drawing of the crusher). The feeding unit is made of mild steel sheet of $6 \mathrm{~mm}$ thickness and the machine dimension is $1050 \mathrm{~mm} \times 525 \mathrm{~mm} \times$ $1250 \mathrm{~mm}$. Hopper is the section through which the waste plastic is fed into the crushing unit. The crushing unit is where the waste plastic is cut into smaller sizes either through shredding or impact force of a shredder or a crusher. The crushing chamber consists of a shaft that is $539 \mathrm{~mm}$ length and $40 \mathrm{~mm}$ in diameter. Attached to the shaft are cutters made of $12 \mathrm{~mm}$ mild steel flat blade of $270 \times 74$ welded to $270 \mathrm{~mm}$ cylindrical drum to form spiral blade. The radius of the spiral blade from the centre of the shaft is $53 \mathrm{~mm}$. There is a clearance $3 \mathrm{~mm}$ between the spiral blade and the adjustable stationary blade. The rubbing of the spiral blade against the stationary blade when the machine is loaded with the materials to be processed brings about the crushing effect on the plates fed in. The spiral blade has the same length with the stationary blade bolted to the blade holder on the member frame in the chamber. Underneath the crushing unit is the screen of $375 \mathrm{~mm}$ length and 392 diameters. The pore space on the screen is $8 \mathrm{~mm}$ in diameter. The crushed plastic passes through an outlet provided at the peripheral of the machine. The outlet dimension is $378 \mathrm{~mm} \times 151 \mathrm{~mm} \times 110 \mathrm{~mm}$. The crushed 
waste plastic discharge freely from the crushing unit through the outlet (See Figure 16 for details). The machine is powered by $10 \mathrm{Hp}$ electric motor with the aid of belt and pulley arrangement (belt drive). The driving and the driven pulley are respectively $100 \mathrm{~mm}$ and $150 \mathrm{~mm}$. Figure 4 below shows the flow chart of processes involved in recycling plastic. The processes are plastic waste collection, screen, sorting, size reduction such as granulation, washing/cleaning, forming into moulds and packaging.

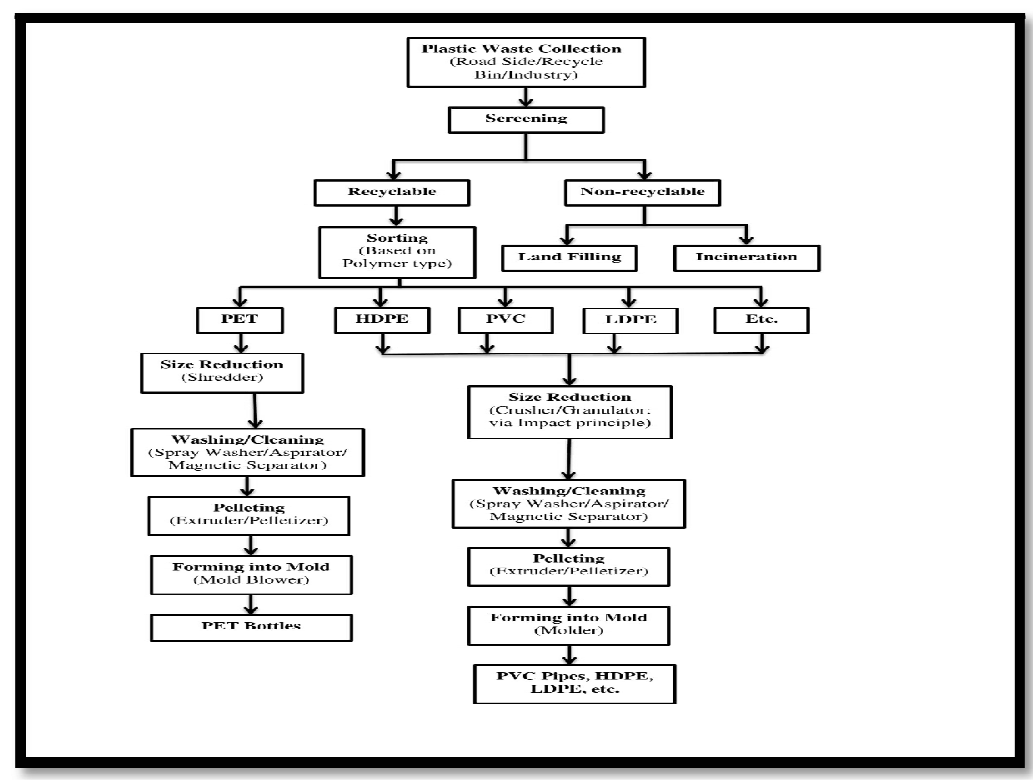

Figure 4: Flow Chart of Plastic Waste Recycling

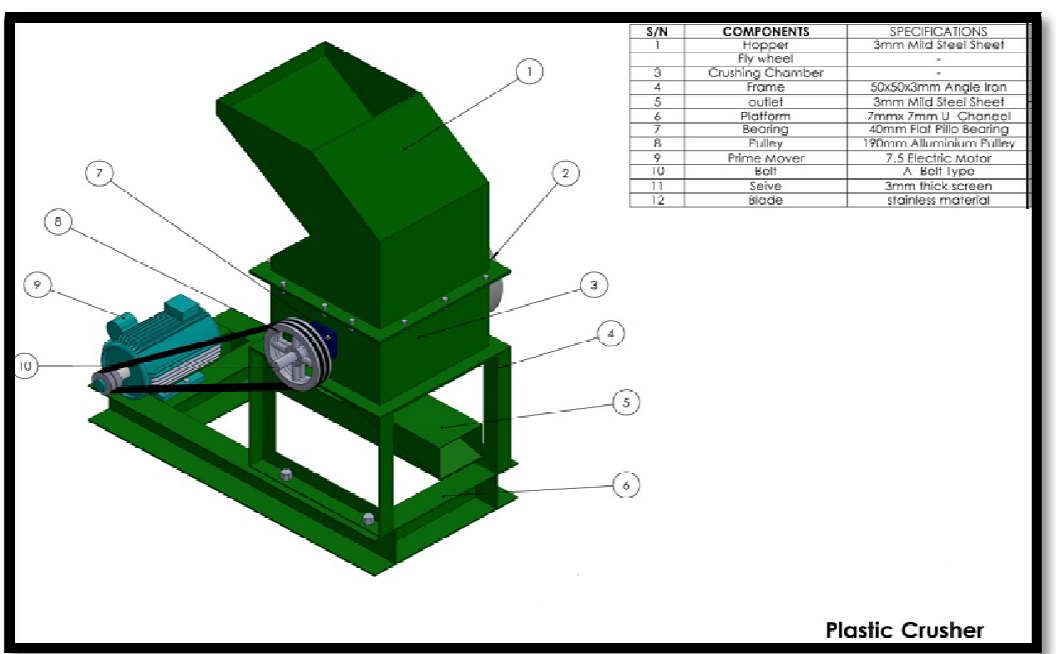

Figure 5: Pictorial View of the Plastic Crusher

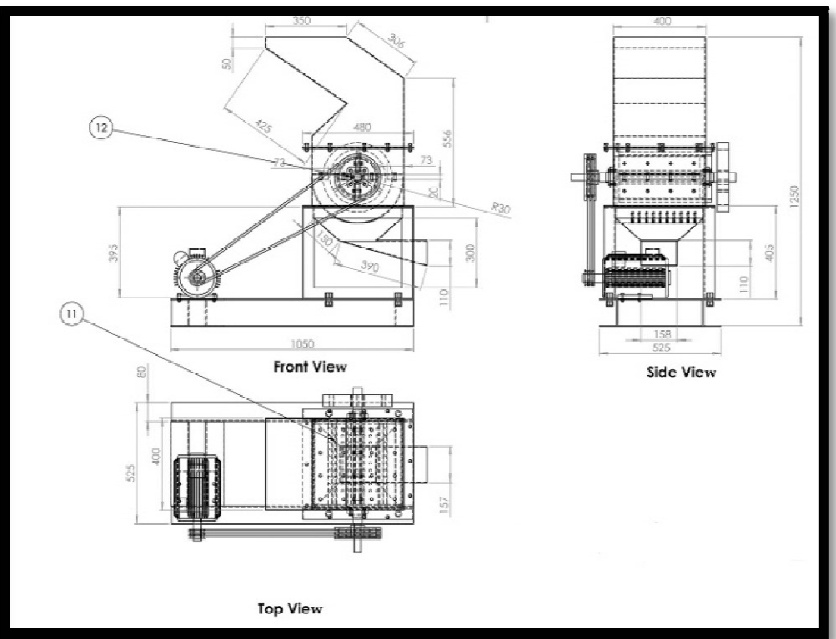

Figure 6: Orthographic Projection of the Plastic Crusher 


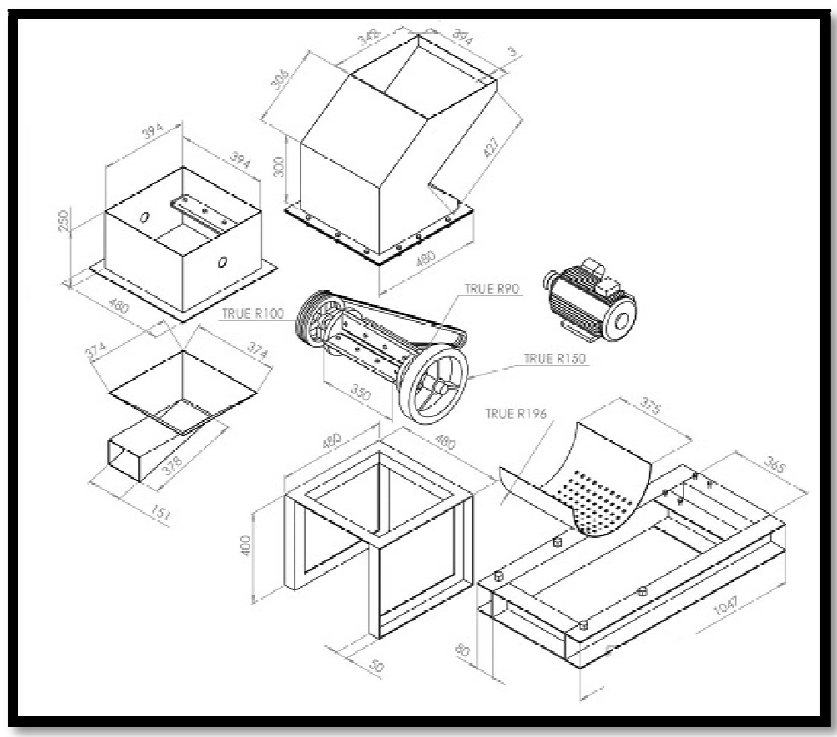

Figure 7: Part Drawings of the Crusher

\subsection{Design Calculation of the Plastic Crusher}

\subsubsection{Hopper Capacity Design}

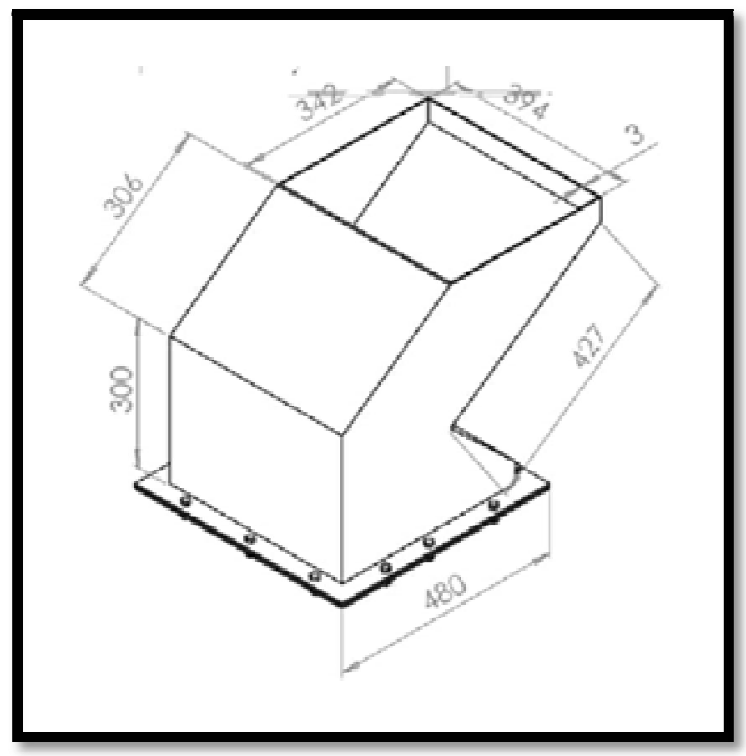

Figure 8: Hopper Design Section

Volume of the hopper $=$ Area of cross-section of the hopper $\times$ width of hopper $=1 / 2(a+b) h \times$ width.

$=1 / 2(245+270) \times 417 \times 245$

(1) (See figure 4 and 5 for details)

Hopper capacity $=26 \times 10^{-3} \mathrm{~m}^{3}$

Volume of PET bottle in the shredding chamber:

Volume of PET bottle (Coca-Cola bottle)

$=$ Area $\times$ height $=\pi \mathrm{d}^{4} / 4 \times \mathrm{h}$.

$=7.7 \times 10^{-4}$

Number of bottles to fill the hopper $=$ volume of hopper $/$ volume of PET Bottle (IJETSR, 2017)

$=26 \times 10^{-3} / 7.7 \times 10^{-4}$

$=34$ bottles

\subsection{Design Calculations}

\subsubsection{Input Power Measurement}

The input power measurement can be determined from the name plate information of the prime mover used to power the machine. It can also be determined from the drive for the transmission shaft of the machine. In this endeavor, the input power for the crusher was calculated from the belt drive used for power transmission. 
$P=\{T 1-T 2\} \times \vee($ Watts $)$

(1) (Hall etal, 1973)

$\mathrm{T}_{1}=$ belt tension in tight side $(\mathrm{N})$

$\mathrm{T}_{2}=$ belt tension in loose side $(\mathrm{N})$

$\mathrm{V}=$ belt speed, $\mathrm{m} / \mathrm{s}$

$\mathrm{V}=\mathrm{wr}$, where $\mathrm{w}=$ angular speed and $\mathrm{r}=$ radius of shaft or pulley under consideration.

In finding the required power, equations 2 , 3and 4 below are needed.

$\{T 1-m v 2\} /\{T 2-m v 2\}=e^{\left\{\frac{f \alpha}{\sin \frac{1}{2} \theta}\right\}}$

(2) (Hall etal, 1973)

$\boldsymbol{\rho}=$ density of belt $=970 \mathrm{~kg} / \mathrm{m}^{3}$ for leather belt

$\theta=180^{\circ}$ or $\pi$ for flat belt, $\mathrm{b}=$ width of belt, $\mathrm{t}=$ thickness of belt

$\mathrm{m}=$ mass in kilogram

\subsubsection{Load Carrying Capacity}

Load carry capacity is calculated for pulley with lower $e^{\left\{\frac{f \alpha}{\sin \frac{1}{2} \theta}\right\}}$ value

For the rice thresher, the following parameters were taken from the design:

$\mathrm{C}=650 \mathrm{~mm}, \varnothing 2=150 \mathrm{~mm}, \varnothing 1=100 \mathrm{~mm}, \quad \mathrm{~b}(15 / 8)=81.28 \mathrm{~cm}, \mathrm{t}(10)=63.5 \mathrm{~cm}$ (Assume B57 belt was used

$\mathrm{C}=$ shaft center distance, $\emptyset 2=$ transmission shaft pulley, $\emptyset 1=$ Motor shaft pully

$m=\rho b t$ (3) (Hall etal, 1973)

$\mathrm{m}=0.0597 \mathrm{~kg} / \mathrm{m}$

$$
m=\frac{\{970 \times 10.8 \times 5.7\}}{\{1000 \times 1000\}}
$$

$N 1 D 1=N 2 D 2$

Where $\mathrm{N}_{1}=\emptyset 1$ = prime mover speed, D1 = Diameter of pulley on prime mover shaft.

$\mathrm{N}_{2}=$ Transmission shaft speed, $\mathrm{D}_{2}=\emptyset 2=$ Diameter of pulley on transmission shaft.

$\mathrm{N}_{1}=1770 \mathrm{rpm}$ (from name plate information of $10 \mathrm{Hp}$ electric motor used), $\mathrm{N}_{2}=$ ? $\mathrm{D}_{1}=100 \mathrm{~mm}, \mathrm{D}_{2}=150 \mathrm{~mm}$

$$
\begin{gathered}
N 1 D 1=N 2 D 2 \\
1770 \times 100=N 2 \times 150
\end{gathered}
$$

From equation 4, Transmission shaft speed, $\mathrm{N}_{2}=1180 \mathrm{rpm}$

$v=9.27 \mathrm{~m} / \mathrm{s}$

$$
v=\frac{\pi D N}{60}=\frac{\{\pi \times 150 \times 1180\}}{\{60 \times 1000\}}
$$

$T 1=b t s$

$$
\text { (5) (Hall etal, 1973) }
$$

Where $\mathrm{s}=$ maximum allowable stress $=2 \mathrm{Mpa}$ for flat belt

From equation 5,

$$
T 1=b t s=\frac{10.8}{1000} \times \frac{5.7}{1000} \times 2 \times 10^{6}
$$

$=123.12 \mathrm{~N}$

Angle of Rap $(\alpha)$

If $\mathrm{f}$ is assumed to be 0.3 , where $\mathrm{f}=$ coefficient of friction between belt and pulley

$\alpha 1=180-2 \beta$,

$\alpha 2=180+2 \beta, \mathrm{c}$ where $\beta=\sin \wedge\left\{-\frac{\mathbf{1}\{\boldsymbol{R}-\boldsymbol{r}\}}{\boldsymbol{C}}\right\}$

Where $\alpha 1$ and $\alpha 2$ are angle of rap for tight and slack side of belt dive.

$\alpha 1=180-2 \sin ^{\wedge}\left\{-\frac{1\{R-r\}}{C}\right\}$

$\alpha 2=180+2 \sin ^{\wedge}\left\{-\frac{1\{R-r\}}{C}\right\}$

$$
\alpha 1=180-2 \sin \wedge\left\{-\frac{1\left\{\frac{150}{2}-\frac{100}{2}\right\}}{650}\right\}
$$

$=180-2 \times 2.204$

$\alpha 1=175.590$

From the formula in equation $7, \alpha 2=184.408^{0}$

From equation $2, e^{\left\{\frac{0.3 \times 175.59 \times \pi / 180}{\sin \frac{1}{2} \theta}\right\}}=2.509$ for $175.59^{0}$, where belt factor $\mathrm{f}=0.3$

Also $e^{\left\{\frac{f \alpha}{\sin \frac{1}{2} \theta}\right\}}=e^{\left\{\frac{0.3 \times 194.86 x \pi / 180}{\sin \frac{1}{2} \theta}\right\}}=2.78$ for $194.86^{0}$. Remember that $\operatorname{Sin} 1 / 2 \theta=\operatorname{Sin} 90=1$, where $\theta=180^{\circ}$

Hence, smaller pulley governs.

From equation 2 again,

$\{T 1-m v 2\} /\{T 2-m v 2\}=e^{\left\{\frac{f \alpha}{\sin \frac{1}{2} \theta}\right\}}$

Therefore,

$\frac{\left\{123.12-0.0597 \times 7.54^{2}\right\}}{\left\{12-0.0597 \times 7.54^{2}\right\}}=2.509$, making $\mathrm{T}_{2}$ the subject, 
$\mathrm{T}_{2}=51.113 \mathrm{~N}$

\subsubsection{Power Requirement}

From equation 1, power requirement is as calculated below:

$v=\frac{\pi D N}{60}=9.27 \mathrm{~m} / \mathrm{s}$

$$
P=\{T 1-T 2\} \times v
$$

$$
P=\{123.12-51.113\} \times 9.27
$$

$=667.51 \mathrm{~W}$

$\approx 0.668 \mathrm{KW}$ (the minimum power required to crush the plastic).

\subsubsection{Motor Name Plate}

Given the following nameplate information about the $10 \mathrm{Hp}$ electric motor used to power the crusher:

$\mathbf{S}_{\mathbf{s}}=$ Synchronous speed in $\mathrm{rpm}=18000$

$\mathrm{S}_{\mathrm{r}}=$ Name plate full load speed $=1750$

$\mathrm{S}_{\mathrm{m}}=$ Measured speed in $\mathrm{rpm}=1770$

$\mathrm{P}_{\mathrm{np}}=$ Nameplate rated horsepower $=10 \mathrm{Hp}$

$\mathrm{P}_{\text {load }}(\mathrm{KW})=60 \%$ of $10 \mathrm{Hp} \times 0.746$

$$
\begin{gathered}
\text { Load }=\frac{\{\text { Slip }\}}{\{S s-S r\}} \times 100 \quad(\%)=\frac{\{S s-S m\}}{\{S s-S r\}} \times 100(\%) \\
\text { Pload }=\frac{\{1800-1770\}}{\{1800-1750\}} \times 100 \\
=60 \%
\end{gathered}
$$

$$
=\frac{60}{100} \times 10 \times 0.746
$$

$=4.476 \mathrm{KW}$ (this is the power of the motor under full load).

The size of the electric motor chosen in terms of power is within range as it can conveniently carry the transmission shaft under full load and high starting torque. i.e. 4.476KW >> 0.668KW. Where the motor has insufficient rating, there will be frequent damages and shut downs due to over loading, and this is not intended.

\subsubsection{Torque Requirement}

Load torques are often times classified as either active load torques or passive load torques. Load torques under consideration in this endeavor is passive type as it is torque due to friction cutting of plastic in the crushing chamber. The torque developed by the motor at the instance of starting is called starting torque and in some cases, it is greater than the normal running torque.

Torque $=(T 1-T 2) R$ (8) (Hall etal, 1973)

$\mathrm{R}=$ Radius of bigger pulley

$=5.40 \mathrm{Nm}$.

$$
\text { Torque }=(123.12-51.113) \times \frac{75}{1000}
$$

\subsubsection{Shear Force and Bending Moment Calculation}

In determining Shearing force and bending moment, certain weights were determined:

Weight of pulley, $\mathrm{W}_{1}=5 \mathrm{~kg} \times 9.81 \mathrm{~N} / \mathrm{m}^{2}=49.05 \mathrm{~N}$

Weight of the four blades on the main shaft in the crushing chamber $\mathrm{W}_{2}=8 \mathrm{~kg} \times 9.81 \mathrm{~N} / \mathrm{kg}=78 \mathrm{~N}$

Weight of the counter balance $\mathrm{W}_{3}=5 \mathrm{~kg} \times 9.81 \mathrm{~N} / \mathrm{m}^{2}=49.05 \mathrm{~N}$

Weight of the main Shaft $\mathrm{W}_{4}=10 \mathrm{~kg} \times 9.81 \mathrm{~N} / \mathrm{m}^{2}=98.1 \mathrm{~N}$

Weight of each bearing, $\mathrm{W}_{5}=5 \mathrm{Kg} \times 9.81=49.05 \mathrm{~N}$

Weight of materials (plastic) to be processed per operation, $\mathrm{W}_{6}=2 \mathrm{Kg} \times 9.81=19.62 \mathrm{~N}$

3.6.6.1. Shear Force Calculation

$\mathrm{R}_{\mathrm{A}}+\mathrm{R}_{\mathrm{B}}=\mathrm{W} 1+\left(\mathrm{W}_{2}+\mathrm{W}_{4}\right)+\mathrm{W}_{6}+\mathrm{W}_{3}=49.05+(78+98.1)+19.62+49.05=293.82 \mathrm{~N}$

$\mathrm{R}_{\mathrm{A}}+\mathrm{R}_{\mathrm{B}}=293.82 \mathrm{~N}$ as shown below (i.e. upward force $=$ downward force)

$\Sigma$ BM: 49.05(50+67.4+67.4+67.4+67.4) + 9.81(67.4+67.4+67.4) + 176.1(67.4+67.4) + 9.81x67.4 -269.5 $\mathrm{R}_{\mathrm{B}}-49.05 \times 50=0$

From there, $269.5 \mathrm{R}_{\mathrm{B}}=39606.936$

$\mathrm{R}_{\mathrm{B}}=146.96 \mathrm{~N}, \quad \mathrm{R}_{\mathrm{A}}+\mathrm{R}_{\mathrm{B}}=293.82$

$\mathrm{R}_{\mathrm{A}}=293.82-146.96=146.86 \mathrm{~N}, \mathrm{R}_{\mathrm{A}}=146.96 \mathrm{~N}$ while $\mathrm{RB}=146.86 \mathrm{~N}$ 


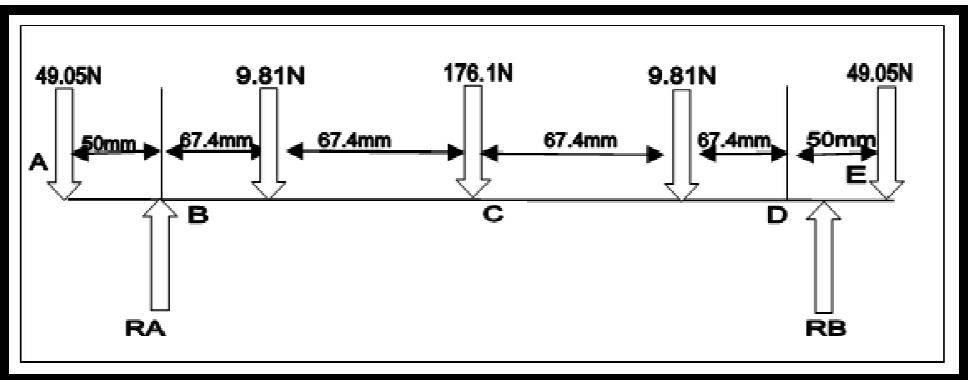

Figure 9: Force Analysis of the Plastic Crusher $R_{A}$ and $R_{B}$ Reaction at Two Bearing Sections

3.6.6.2. Bending Moment Calculation

1. Bending Moment at $A=49.05 \times\{269.5+50\} / 1000 \mathrm{Nm}=-15.67 \mathrm{Nm}$

2. Bending Moment at $B=146.86 \times 269.5 / 1000=39.58 \mathrm{Nm}$

3. Bending Moment at $C=\{(9.81+176+9.81) \times 134.8\} / 1000=-26.37 \mathrm{Nm}$

4. Bending Moment at $\mathrm{D}=169.18 \times 0=0$

5. Bending Moment at $\mathrm{E}=\{49.05 \times 50\} / 1000=2.45 \mathrm{Nm}$

\subsubsection{Shear Force and Bending Moment Diagram}

Weight of main shaft, Ws $=50 \mathrm{~N}$. Also, weight Wj of materials in the hopper section is $40 \mathrm{~N}$. Assume weight of section of four blades on the main shaft to be $W w=80 \mathrm{~N}$ altogether. Therefore, different forces acting on the main shaft are as analysed above in figure 9.

Shear force and bending moment diagram are as in figure 7 below.

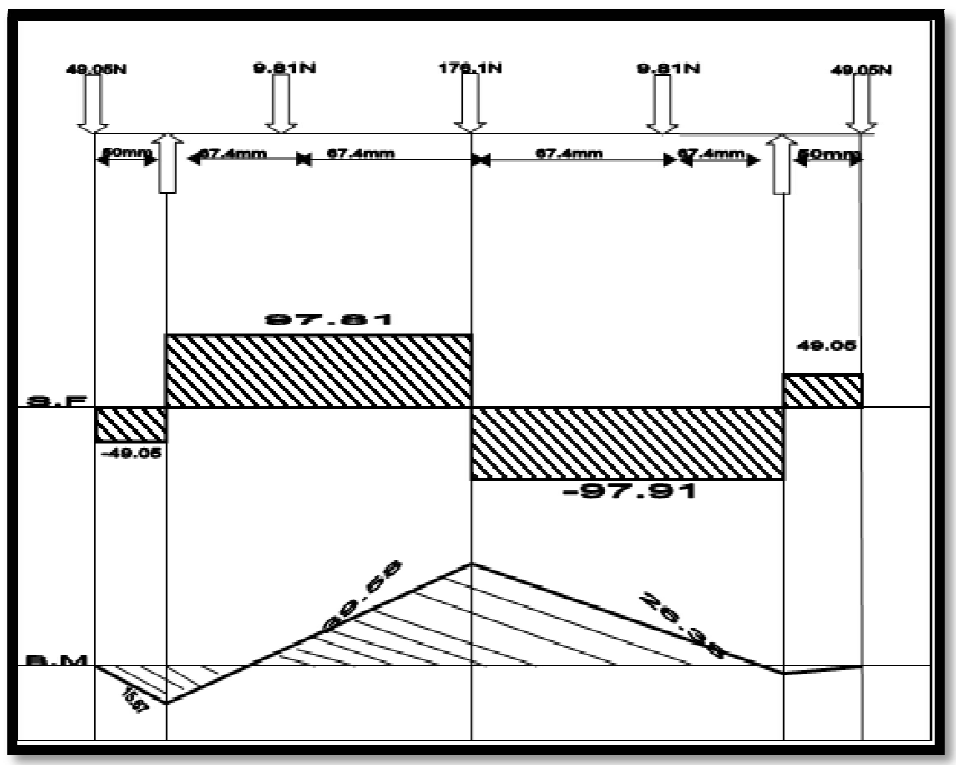

Figure 10: Shear Force and Bending Moment Diagram

\subsubsection{Transmission Shaft Design}

Shaft design consists primarily of the determination of the correct shaft diameter to ensure satisfactory strength and rigidity when the shaft is transmitting power under various operating and loading conditions. Shafts are usually in cross-section, and may be either hollow or solid. The shaft considered for design in this technical report is solid cylindrical shaft. See figure 8 below for details.

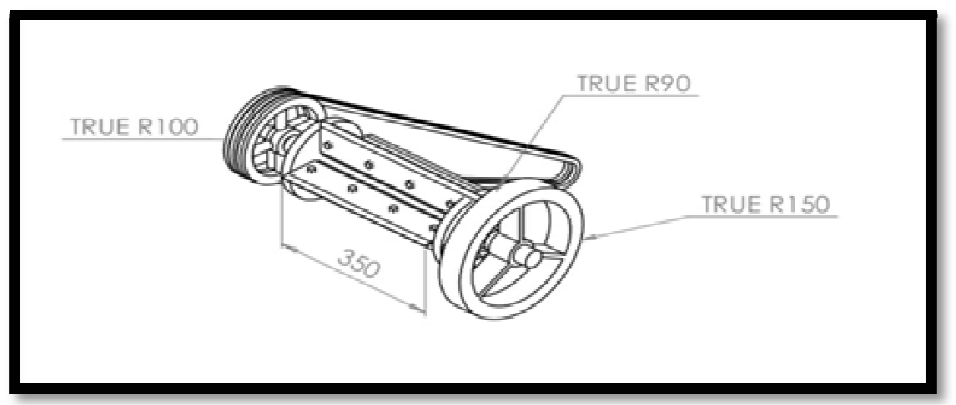

Figure 11: Shaft Design Section 
The ASME code equation for solid shaft diameter is as given in equation in equation 10 below.

$d^{3}=\frac{16}{\pi S s} \sqrt{\left\{(k b M b)^{2}+(K t M t)^{2}\right\}}$ (10) (Hall etal, 1973)

$\mathrm{Mb}=$ bending moment

Mt $=$ Torsional Moment

$\mathrm{Kb}=$ combined torque and fatigue factor applied to bending moment

$\mathrm{Kt}=$ combined torque and fatigue factor applied to torsional moment

From ASME code, $\mathrm{S}_{\mathrm{s}}=40 \mathrm{MN} / \mathrm{m}^{2}$ for shaft with key

Also, $\mathrm{K}_{\mathrm{b}}=1.5, \quad \mathrm{~K}_{\mathrm{t}}=1.0$

From the bending moment calculation above, $\mathrm{Mb}=39.58 \mathrm{Nm}$. Torsional moment, $\mathrm{Mt}=502.66 \mathrm{Nm}$ (See equation 13 for details of the value)

$\mathrm{M}_{\mathrm{b}}=39.58 \mathrm{Nm}$ (see bending moment diagram for details)

$$
\begin{gathered}
d^{3}=\frac{16}{\pi \times 40 \times 10^{6}} \sqrt{\left\{(1.5 \times 39.58)^{2}+(1.0 \times 502.66)^{2}\right\}} \\
d^{3}=\frac{16}{\pi \times 40 \times 10^{6}} \sqrt{\{3524.80+252667.1\}} \\
d^{3}=\frac{16}{\pi \times 40 \times 10^{6}} \sqrt{256191.9}
\end{gathered}
$$

$\mathrm{d}=\sqrt[3]{\{0.0000644455\} \mathrm{m}}$

$\mathrm{d}=40.09 \approx 40 \mathrm{~mm}$. Therefore, the minimum diameter that can be chosen as transmission shaft diameter for the crushing chamber is $40 \mathrm{~mm}$.

\subsubsection{Shaft Design for Torsional Rigidity}

Rigidity is based on the permissible angle of twist. The amount of twist permissible depends on the particular application, and varies about $0.3^{0} / \mathrm{m}$ for machine tool shafts to about $3^{0} / \mathrm{m}$ for line shafting.

According to SAME on solid circular shaft,

$\theta=584 M t L / G d^{4}$

$\theta=$ angle of twist (degree)

$\mathrm{L}=$ length of shaft $(\mathrm{m})=800 \mathrm{~mm}$ - designed

Mt =torsional moment $(\mathrm{Nm})=11.13 \mathrm{Nm}$ - calculated

$\mathrm{G}=$ torsional modulus of elasticity $\left(\mathrm{Nm}^{2}\right)=80 \times 10^{9} \mathrm{Nm}^{2}-$ standard

$\mathrm{d}=$ shaft diameter $=40 \mathrm{~mm}-$ Assumed value.

$\mathrm{R}=\mathrm{D} / 2=40 / 2=20 \mathrm{~mm}=0.02 \mathrm{~m}$

$$
\theta=\frac{\{584 \times 502.66 \times 0.8\}}{\left\{80 \times 10^{9} \times 40.0^{4} \times 10^{-12}\right\}}=\frac{\{234842.752\}}{204800}
$$

$\theta=1.15^{0}$. Since the value is less than $3^{0} / \mathrm{m}\left(3^{0} / \mathrm{m} \gg>1.43^{0} / \mathrm{m}\right)$, angle of twist of the $0.8 \mathrm{~m}$ long transmission shaft is within permissible range.

Torsional moment, $\mathrm{Mt}=\frac{\{S s \times \mathrm{J}\}}{R}$

Where J is Polar Moment of inertia of a circular solid shaft, Ss is maximum shear stress and $\mathrm{R}$ the radius of the shaft.

$$
J=\frac{\pi R^{4}}{2}=\pi x \frac{\left(\frac{20}{1000}\right)^{4}}{2}=2.5133 \times 10^{-7} \mathrm{~m}^{4}
$$

Since Ss $=40 \mathrm{MNm}^{2}$, therefore:

$\mathrm{Mt}=\frac{\left\{40 \times 10^{6} \times 2.5133 \times 10^{-7}\right\}}{0.02}$

$\mathrm{Mt}=502.66 \mathrm{Nm}$

\subsection{Experimental Procedure}

The description of a typical experiment was used to explain the experimental procedure. Plastic crusher uses impact principle to crush plastic fed into it. During working process, its prime mover drives the transmission shaft of the machine with a high-speed and strong impact force. This speed is then transmitted to the rotating blade cutter head which in turn forms the relative movement trends cooperated with fixed blade. However, utilizing the gap between rotating blade and fixed blade gives rise to cutting edges of plastic grinding and cutting, thereby crushing the large pieces of plastic. Lastly, the broken plastic is filtered and outputted according to particles sizes of plastic through the screen sieve provided at the peripheral of the machine.

\subsection{Materials for Evaluation and Variables Considered}

Materials used for plastic crusher evaluation are HDPE, LDPE, PET Bottle and PVC, Sensitive measuring scale, stop watch and recording materials. Variables considered during evaluation are blade clearance, screen size, material throughput, machine capacity, polymer type and efficiency.

\subsection{Method of Analysis of Results}

Null hypothesis for variables considered is Ho: $0.5 \leq \mathrm{r} \leq 1$; while alternative hypothesis is H1: $\mathrm{r}<0.5$. For Ho in the range of values stated above, it means there is a strong relationship between the dependent variable and independent 
variable. If the correlation coefficient is not within acceptable region, alternative hypothesis is accepted. The implication of this is that the relationship between them is weak.

$\mathrm{a}=\overline{\mathrm{y}}-\mathrm{b} \ddot{\mathrm{x}}$

From equation 14 above, regression line ' $y=b x+a$ ' can be determined. Relationship between the observed variables and the predicted variables was established through statistical instrument (see the annex of this report for details of the calculation).

\subsection{Cost Estimation of Plastic Crusher}

Cost of engineering products like newly developed plastic crusher can broadly be grouped under direct or indirect cost (Haslehurst, 1981). Direct cost is the cost of factors which are directly attributed to the manufacture of a specific product (i.e. materials and labour costs). Indirect cost on the other hand is that indirectly attributed to the manufacture of a specific product, such as overhead cost (usually expressed in percentage of direct labour cost) (Ajav et al, 2018).

The costing of the newly designed and fabricated plastic crusher was based on the detailed factorial estimate method (Sinnot, 1993). This is because fabrication of the machine is complete and detailed breakdown and estimation of component parts is possible. The cost analysis of the machine is shown in table 2 below.

\begin{tabular}{|c|c|c|c|}
\hline Qty. & Material Specifications & $\begin{array}{l}\text { Rate } \\
\text { (N) }\end{array}$ & $\begin{array}{c}\text { Amount } \\
\text { (N) }\end{array}$ \\
\hline 3 & Angle Iron One Length, $70 \mathrm{~mm} \times 70 \mathrm{~mm}$ & 7,500 & 22,500 \\
\hline 1 & Mild Steel Solid Shaft $1 \mathrm{~m}$ long, $\phi 40 \mathrm{~mm}$ & 10,000 & 10,000 \\
\hline 20 & Mild Steel Bar $20 \mathrm{~mm}$ x $5 \mathrm{~mm}$ x $1 \mathrm{~m}$ & 250 & 5,000 \\
\hline 2 & Flange bearing $\phi 25 \mathrm{~mm}$ & 3,500 & 7,000 \\
\hline 2 & Mild Steel Figure $122 \mathrm{~mm} \times 244 \mathrm{~mm} \times 10 \mathrm{~mm}$ & 30,000 & 60,000 \\
\hline 2 & Pkt. Mild Steel Electrode Gauge 12 & 4,000 & 8,000 \\
\hline 1 & Mild Steel Plate $60 \mathrm{~mm} \times 80 \mathrm{~mm} \times 10 \mathrm{~mm}$ thickness & 7,000 & 7,000 \\
\hline 36 & Bolts \& Nuts M10Hcx. $13 \mathrm{~mm}$ & 50 & 1,800 \\
\hline 2 & Cutting Stones $\phi 230 \mathrm{~mm}$ size $2.5 \mathrm{~mm}$ & 500 & 1,000 \\
\hline 3 & Grinding Stones $\phi 180 \mathrm{~mm}$ thickness $5 \mathrm{~mm}$ & 500 & 1,500 \\
\hline 2 & Hack Saw Blades 320mm long & 75 & 150 \\
\hline 2 & Drill Bits $13 \mathrm{~mm} \& 14 \mathrm{~mm}$ & $250 \& 300$ & 550 \\
\hline 1 & Counter Balance Weight (5kg) & 5,000 & 5,000 \\
\hline 6 & Blade $269 / 74 \mathrm{~mm}$ & 80,000 & 80,000 \\
\hline 1 & Electric motor $10 \mathrm{Hp}$ & 80,000 & 80,000 \\
\hline- & Transport & 7,000 & 7,000 \\
\hline \multicolumn{4}{|c|}{$\begin{array}{l}\text { Sub Total = } 226,520 \\
\text { DIRECT LABOUR COST } \\
\text { Machining of Main Shaft Worms and Spiral Blade } \\
\text { Fabrication (Bending, Rolling, Shearing, welding, painting) } \\
\text { Sub Total = } \$ 15,000 \\
\text { INDIRECT/OVERHEAD COST } \\
\quad \text { 1. Over head of direct material cost }=20 \% \text { of } \$ 15,000=\$ 3,000 \\
2 . \quad \text { Over head of direct labour cost }=20 \% \text { of } \$ 226,520=\$ 45,304 \\
\text { Sub Total = } \$ 48,304\end{array}$} \\
\hline
\end{tabular}

Table 2: Bill of Engineering Measurement and Evaluation (Beme) of the Plastic Crusher Mechanical Components (Direct Material Cost)

\section{Results and Discussion}

\subsection{Result}

Plastic Crushing is the process of transferring an impact force amplified by a mechanical advantage to a material made of molecules that are bond together more strongly and as well resist deformation. In the evaluation process, large materials were fed into the machine for crushing exercise. The machine mainly consists of a cutter whose principle is to destroy the plastic into granules depending on the shear force and impact strength applied. The essence of crushing is to reduce large solid material object into a smaller piece. It is usually used to reduce size and shape of materials so that it can be efficiently used for the purpose intended. The results from evaluation work are as shown in tables 3, 4, 5 and charts 1,2 , 3 and 4below. The recyclable polymers used to test the efficiency; material throughput and versatility of the machine are low density polyethylene (LDPE), high density polyethylene (HDPE), polyethylene terephthalate (PET) bottles and polyvinyl chloride (PC). Variables evaluated are material throughput, blade clearance, size of screen, nature of materials processed and efficiency. 


\begin{tabular}{|c|c|c|c|c|c|c|c|}
\hline S/N & Polymer Type & \multicolumn{2}{|c|}{$\begin{array}{c}\text { Weight of Crushed } \\
\text { Polymer (Kg) }\end{array}$} & $\begin{array}{c}\text { Time } \\
\text { Taken } \\
\text { (Hr.) }\end{array}$ & $\begin{array}{c}\text { Material } \\
\text { Throughput } \\
\text { (Kg/Hr.) }\end{array}$ & $\begin{array}{c}\text { Tonnage/day } \\
\text { (tonnes/day) }\end{array}$ \\
\hline & & $\mathbf{W}_{\mathbf{1}}$ & $\mathbf{W}_{\mathbf{2}}$ & $\mathbf{W}_{\text {avg. }}$ & & & \\
\hline 1 & HDPE & 76.5 & 78.8 & 77.70 & 1 & 77.70 & 0.622 \\
\hline 2 & LDPE & 62.4 & 62.7 & 62.60 & 1 & 62.60 & 0.501 \\
\hline 3 & PC & 41.5 & 41.8 & 41.70 & 1 & 41.70 & 0.334 \\
\hline 4 & PET & 2.1 & 2.2 & 2.15 & 1 & 2.15 & 0.017 \\
\hline
\end{tabular}

Table 3: Result from Crushing Exercise Using Different Polymer Type (2mm Crushing Blade Clearance)

\begin{tabular}{|c|c|c|c|}
\hline S/N & $\begin{array}{c}\text { Rotary to Stationary } \\
\text { Blade Clearance (mm) }\end{array}$ & $\begin{array}{c}\text { Material Throughput } \\
\text { (Kg/Hr.) }\end{array}$ & Tonnage/Day (tonnes/day) \\
\hline 1 & 1.0 & 84.2 & 0.6736 \\
\hline 2 & 1.5 & 79.6 & 0.6368 \\
\hline 3 & 2.0 & 73.3 & 0.5864 \\
\hline 4 & 2.5 & 49.8 & 0.3984 \\
\hline 5 & 3.0 & 21.56 & 0.1725 \\
\hline
\end{tabular}

Table 4: Result from HDPE Crushing with Varied Crushing Blade Clearance

\begin{tabular}{|c|c|c|c|}
\hline S/N & Screen Clearance (mm) & $\begin{array}{c}\text { Material Throughput } \\
\text { (Kg/Hr.) }\end{array}$ & Tonnage/day (tonnes/day) \\
\hline $\mathbf{1}$ & 8.0 & 78.9 & 0.6312 \\
\hline $\mathbf{2}$ & 6.0 & 67.6 & 0.5408 \\
\hline $\mathbf{3}$ & 4.0 & 50.4 & 0.4032 \\
\hline $\mathbf{4}$ & 2.0 & 30.5 & 0.244 \\
\hline
\end{tabular}

Table 5: Result from HDPE Crushing with Varied Screen Clearance (1.5mm Crushing Blade Clearance)

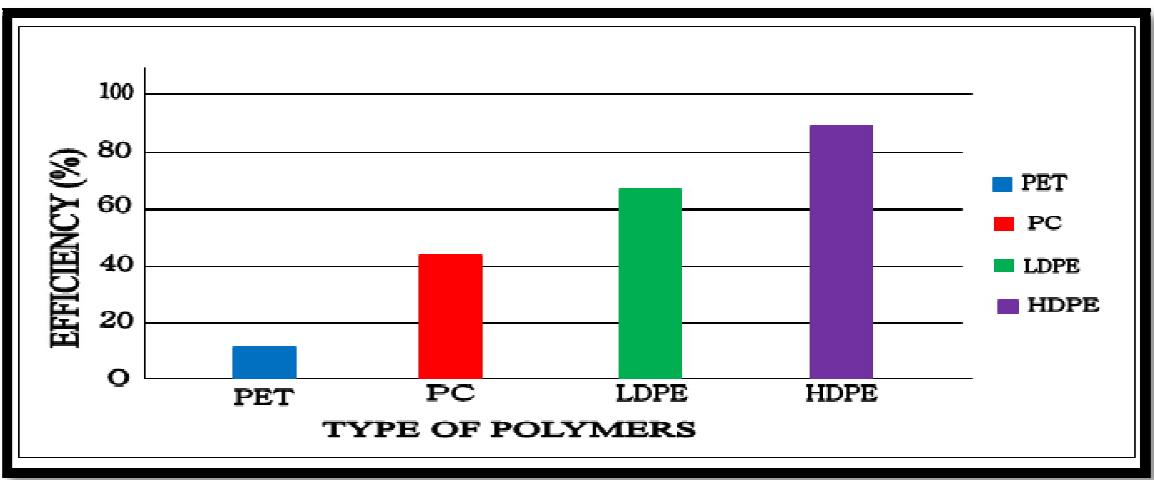

Figure 12: Relationship between the Polymer Type and Efficiency of Crushing

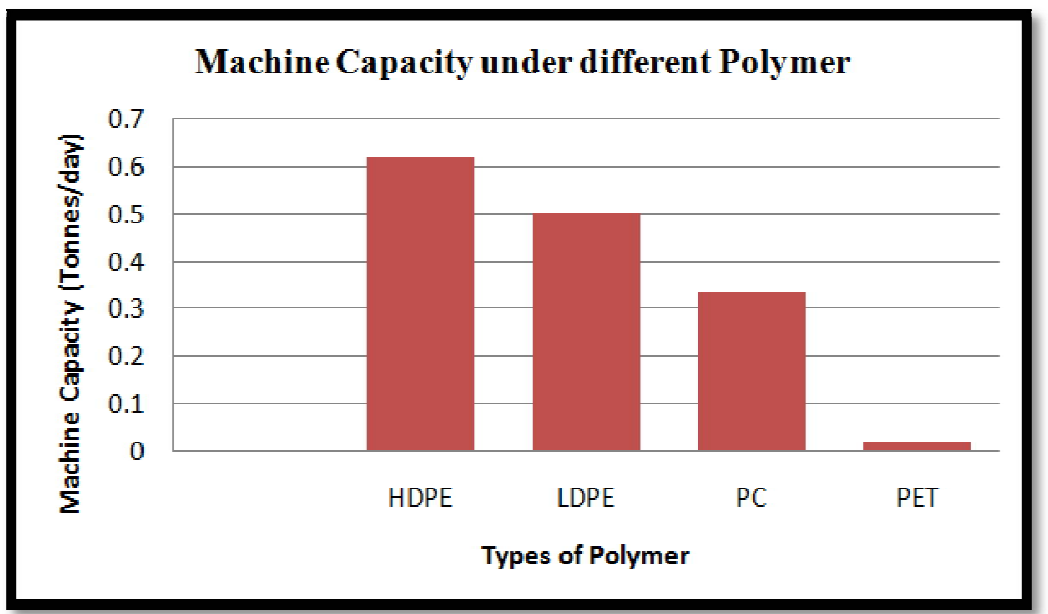

Figure 13: Plastic Crusher Capacity Based on Polymer Type Processed 


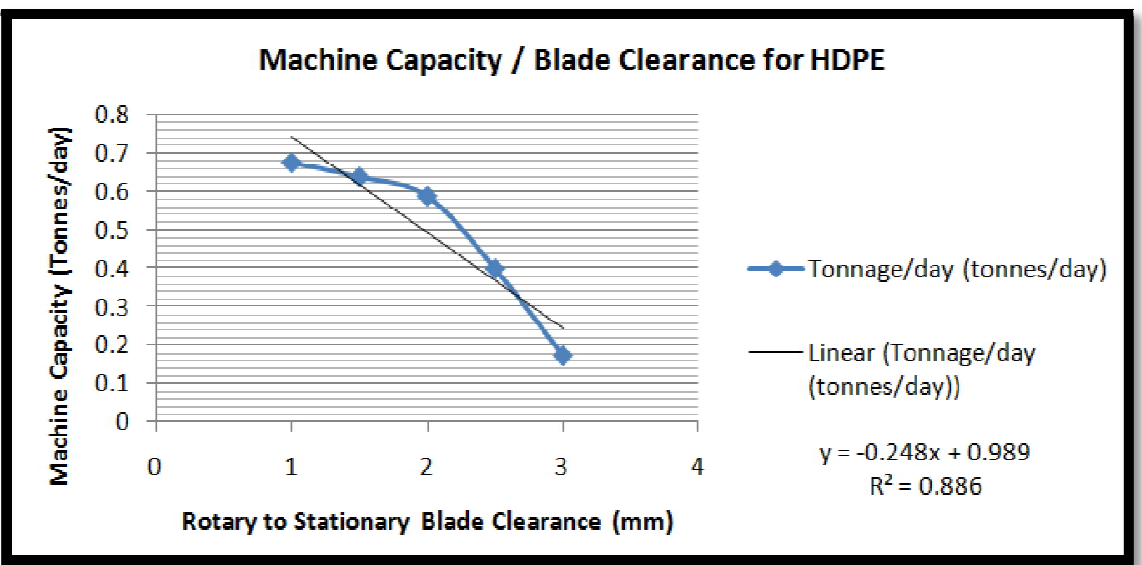

Figure 14: Relationship between Machine Capacity and Blade Clearance

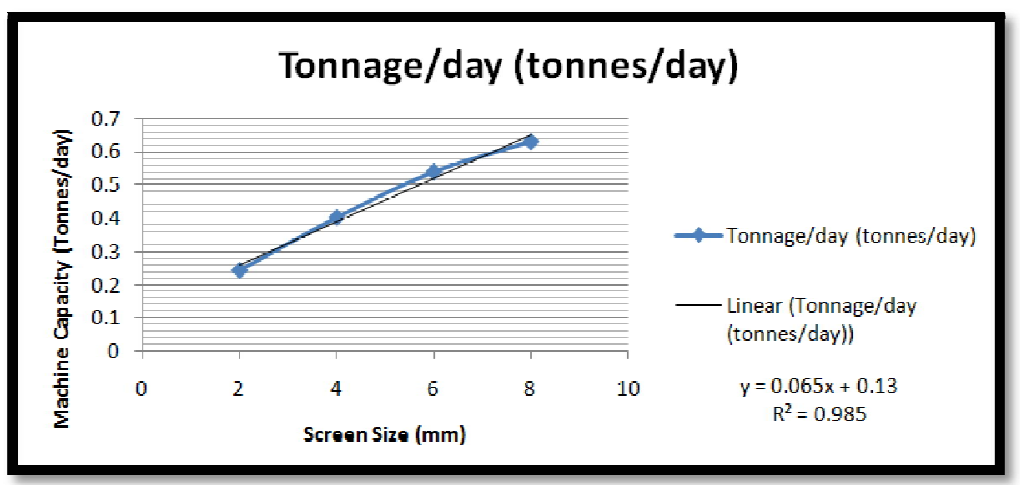

Figure 15: Relationship between Material Throughput and Screen Sizes

\subsection{Discussion}

Plastic crusher was designed, developed and subjected to performance evaluation in Agricultural and Bioenvironmental Engineering Department, FPI, Ilaro, Ogun State, Nigeria. The test result is as shown in tables 3 to 5 and Charts 1 to 4 . The sectioned view of the developed plastic crusher is as shown in Figure 16. The view shows the shaft section, spiral blade, stationary blade, pillow bearings, pulley and the counter weight. Once the machine is powered with a 3-phase electric motor at a medium speed of $1440 \mathrm{rpm}$, the spiral blade rubs the plastic to be crushed against the stationary blade through impact force to crush the plastic.

Results in Figure 12 and 2 above show that the machine is more versatile for HDPE crushing as compared to other types of polymer as both efficiency (90\%) and materials throughput (above $600 \mathrm{~kg} /$ day) for the polymer are the highest. This could be due to hardness of the material. Efficiencies of various type of polymers processed are $90 \%$ for HDPE, $68 \%$ for LDPE, $45 \%$ for PVC and 10\% for PET bottles. When PET bottles were processed, the machine capacity was $17 \mathrm{~kg}$ per day of 8 hours operation. This could be due to soft nature of the material as it tends to draw instead of braking at strong impact force. Direct implication from this is that the machine is not suitable for pet bottles crushing. Shredder should rather be used by processor for materials of that nature.

A plastic shredder is a machine used to cut plastic into smaller pieces for granulation. In the process, large plastic items are fed into the shredder which moves at a slower speed than a granulator or crusher. The blades arranged on the transmission shafts rotating in an interwoven manner break the plastic down into smaller chunks. The shredder can tear up and recycle waste recyclable resources such as waste PET bottles, waste rubber and wastes tires as against crusher which uses strong impact force to brake hard plastic materials.

In Figure 14, the clearance between the stationary and rotary blade was adjusted at various intervals between $1 \mathrm{~mm}$ to $3 \mathrm{~mm}$ to determine if the adjustment has effect on material throughput - the clearance can be adjusted to suit crushing condition needed. It was observed that if the clearance is too low (below $1 \mathrm{~mm}$ ); it can lead to clogging of parts and eventual machine seizure. For too large clearance, the impact force needed for effective material crushing will not be attained. The minimum clearance for smooth running of the machine should be in the range of $1 \mathrm{~mm}$ and $2 \mathrm{~mm}$; above $2 \mathrm{~mm}$, material throughput will take a downward trend. R-squared of the regression line for this case is 0.8861 , meaning there is strong relationship between observed variable(machine capacity) and predicted variable (blade clearance).Rsquared is a statistical measure of how close the data are to the fitted regression line $-\mathrm{R}^{2}$ quantifies the degree of linear correlation between observed value and predicted value.

The screen size provided for crushed material flow into outlet provided at the peripheral of the machine is in the range of $8 \mathrm{~mm}$ to $2 \mathrm{~mm}$. It was observed that the size of screen has impact on material throughput since measure of the degree of linear correlation between the two variables is high $\left(R^{2}=0.9858\right)$. The bigger the screen size the higher the material throughput in an hour (see Figure 15 and table 5 for details). The machine capacity is above 600kg in a day of 8 hours operation for $8 \mathrm{~mm}$ screen size with HDPE crushing and a bit above $200 \mathrm{~kg}$ for $2 \mathrm{~mm}$ screen size - the bigger the size 
of screen, the higher the material throughput. Figure 17 shows the picture from the crushing exercise and the sizes of crushed plastic observed varied from $8 \mathrm{~mm}$ to a granular size of particulate matter.

It appears the screen size used for the crusher design is small since materials above 8mm cannot flow easily through it. This in turn affects the feeding rate of plastic into the machine. The processing time for certain kilogram of plastic to be crushed can be increased if the screen directly under the crushing chamber is changed to the type in the range of $12 \mathrm{~mm}$ to $20 \mathrm{~mm}$.

When the machine is in operation, all parts are set in motion due to vibration of major parts like the transmission shaft. The vibration of parts brings about spill of materials under process out of the machine through the hopper. Lid can be provided for the hopper to prevent material flow out of the machine through the hopper section.

The medium speed (1440 rpm) electric motor used can also be changed to high speed (2900 rpm) motor. This will make the impact force on the machine to be high enough to crush the type of polymer under process. In good turn, the machine throughput will be high.

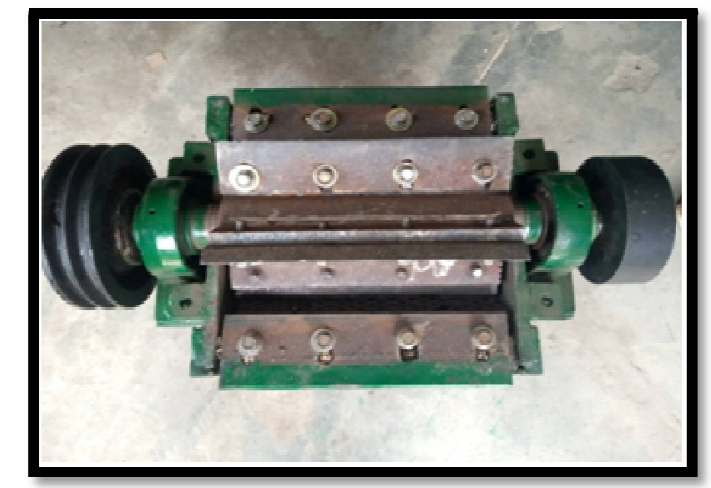

Figure 16: Section View of the Plastic Crusher with the Shaft and the Spiral Blade

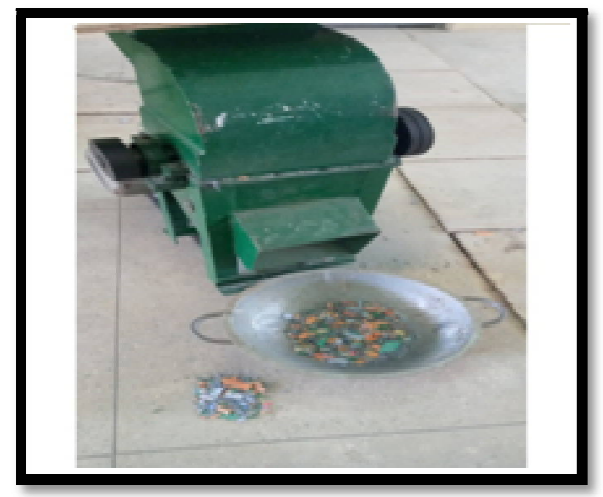

Figure 17: Plastic Crusher during One of the Crushing Exercises

\section{Conclusions and Recommendations}

\subsection{Conclusions}

The plastic crusher is widely used in industries for plastic waste management. By using this plastic crushing machine, the overall costing of recycling process is reduced and labour work becomes less. To recycle waste plastic into other forms of plastics, the following machines are involved: Plastic crusher/shredder, extruder, granulating machine, washing machine, bale breaker, plastic melting and moulding machine etc. This technical brief focused on plastic crusher. The following are the conclusions from the evaluation work carried out on the machine:

- The plastic crusher is not a suitable machine for PET bottle recycling.

- The screen size used for the crusher design is small since materials above 8mm cannot flow easily through it. This in turn affects the feeding rate of plastic into the machine.

- When the machine is in operation, all parts are set in motion due to vibration of major parts like the transmission shaft. The vibration of parts brings about spill of materials under process out of the machine through hopper. Lid can be provided for the hopper to prevent material flow out of the machine.

- The plastic crusher can only be used for small scale recycling of plastic.

- The efficiencies of various type of polymers processed are 90\% for HDPE, $68 \%$ for LDPE, $45 \%$ for PVC and $10 \%$ for PET bottles. Direct implication from this analysis is that the machine is not suitable for crushing PET bottles. Shredding machine should rather be used for materials of that nature by processors in the industry. 


\subsection{Recommendations}

- The processing time for certain kilogram of plastic to be crushed can be increased if the screen directly under the crushing chamber is changed to the type in the range of $12 \mathrm{~mm}$ to $20 \mathrm{~mm}$.

- The medium speed (1440 rpm) electric motor used can also be changed to high speed (2900 rpm) motor. This will make the impact force on the machine to be high enough to crush the type of polymer under process. In good turn, the machine throughput will be high.

- The machine versatility for other waste materials like paper waste, tin can, etc., should be tested.

- The speed of the electric motor should be increased and the material should be exposed to sunlight radiation for a long time before they are processed.

- Thorough evaluation can be carried out on the machine as data from it will assist in optimization of its process efficiency.

- The machine can be adopted for commercialization if modification work aforementioned is carried out on it.

- The plastic of the same materials should be crushed to make materials processed per time attract high market value.

\section{References}

i. Ajav E.A., Okusanya M.A. and Obi O.F. (2018). Jatropha Oil Extraction Optimization through Varied

ii. Processing Conditions Using Mechanical Process. International Journal of Innovative Research \& Development.Doi No.: 10.24940/Ijird/2018/V7/I9/Sep18058. Page 227 - 241, accessed June, 2020.

iii. Akmal Bin Uzir, Khairuddin Bin Ishak, Norhafizah Akmal Binti Sukri [2014] The design \& built of crusher machine plastic bottles, Volume -1, pg.no.184-189, 2014

iv. Amandeep Aggrawal (May, 2019). What are we doing to stop plastic menace. Down to earth. (www.downtoearth.org, accessed September, 2019).

v. Eric Beckman. (2018). The worid`s plastic problems in number. www.weform.org. International Journal of Scientific and Engineering Research, Volume 7, Issue 5, May- 2016 ISSN 2229-5518

vi. Haslehurst, M. (1981). Manufacturing Technology (3rd edition). Academic and Medical Publishing Division of Hodder and Stronghton, Bedford Square, London.

vii. International Journal of Engineering Technology Science and Research IJETSR www.ijetsr.com ISSN 2394 3386 Volume 4, Issue 10 October 201

viii. Jambeck JR, Geyer R, Wilcox C, Siegler TR, Perryman M, et al. (2015) Plastic waste inputs from land into the ocean. Science 347: 768-771.

ix. Knox, Andrew (February 2005). 'An Overview of Incineration and EFW Technology as Applied to the Management of Municipal Solid Waste (MSW)' (PDF). University of Western Ontario. Archived from the original (PDF) on 5 December 2008.

X. NitulLimbasia, Rashmita Thummar. Amita Upadhyay [2015] Recycling of plastic waste-An overview eISSN:2394-3343, volume-2, issue2, pg.no.43-45, 2015.

xi. P. Vindis, B. Mursec, C. Rozman, M. Janzekovic, F. Cus, Biogas production with the use of mini digester, Journal of Achievements in Materials and Manufacturing Engineering 28/1 (2008) P. 99-

xii. RRN Sailaja Bhathachanya, Kaushik Chandra Sekhar, MvDeepth, Pratik Roy, and Ameen

xiii. Khan [2018] Challenges and opportunities plastic management in India.www.researchgate.net.

xiv. Sinnot, R.K. (1993). Chemical Engineering Volume 6. An Introduction to Chemical Engineering Design. (1 ${ }^{\text {st }}$ edition). Pergamon International Library, Oxford New York.

xv. S.B.SatishJ.Saisandeep, B.SreehariYeshwant, M. Sonkhaskar [2016] Designing of a Portable Bottle Crushing Machine,ISSN:2321-0613, Volume4, Issue 07, pg.no.891-893, 2016. 102.

xvi. Mercy Joseph Poweth, Solly Geo and Jessy Paul (2018). Study on Use of Plastic Waste in Road. International Journal of Innovative Research in Science, Engineering and Technology.

xvii. Vanessa Goodship (2007).'Introduction to Plastics Recycling'. 2nded, iSmithers Rapra Publishing. 